\title{
Reflection and Exploration of Prescription Education on Physical Exercise in Vocational College
}

\author{
Pengyi Yan \\ Xi'an International University, Xi'an, 710077, China
}

\begin{abstract}
Keywords: Pyhsical education in vocational college, Exercise prescription education, Reflection, Exploration
\end{abstract}

\begin{abstract}
In the education in vocational college, the new curriculum requires to educate students from all-dimensional way. In this background, the position of physical education promotes rapidly. To carry out pyhsical education and break traditional teaching model, teachers applies new way----the exercise prescribed teaching. The effective application of this mode could not only present positive view of life and exercise, but also break restrictions of traditional teaching and develop the promotion of physical education in vocational college. This paper takes an deep analysis on prescription education and introduces own view, and hope to give some assistance to carry out physical education.
\end{abstract}

\section{Introduction}

"Physical capital is revolutionary", this sentence indicates the importantance of physical health. Whenever in previous and modern times, or the future, physical health is very important. Only by a healthy body, we could have abilities to pursue dream and work. Therefore, there are more and more attention on physical education. In vocational college, gym instructors have applied exerciseprescribed teaching which has achieve remarkable results. Now this mode is the main teaching approach in vocational college.

\section{The traditional teaching mode in physical education in Vocational College}

\section{Competitive Mode}

In pyhsical education of vocational college, the common mode is competitive mode. This mode is proposed by American scholas and it costs a lot. Teachers want to help students to obtain one competitive physical activity for a amount of time. The specific procedures are that: at first, teachers teach student the basic skills of sports; then , teachers find some sport videos for students, and let students learn something from the video; and teachers provide some practical activities for students, so that students could sharpen their skills and learn some tactical strategies; at last, students could grasp this activity through practices.

\section{Transfer - accept model}

Transfer- accept model is a very traditional teaching mode. This model take inheritance of human civilizaiton as a teaching objective. It is to say that the aim of this model is to help student grasp physical skills and pass it to the next generation. The character of this model is that the teachers are the subject of classroom, and teachers are unique, students only accept these lessons passively and their status have been ignored. As a result, students learns with low interests, and the teaching objective is not implemented. The specific procedures are that: at first, teachers teach knowledge, teachers teach and students learn in the class; the second step, teachers will help students learn and understand these knowledge through work practice; the third step, retention and application. After students learn these skills from teachers, teachers would organize team competition to help students; the forth step, examination and evaluation, teachers need to evaluate students with their real practice, and point out insufficient and improve their mastering level of these knowledge ${ }^{[1]}$.

In conclusion, these two physical teaching model are not able to keep pace with development tendency. To carry out pyhsical education, teachers applies new way----the exercise prescribed teaching. The following are analysis on the exercise prescribed teaching. 


\section{The contents and stage division of the exercise prescribed teaching in vocational college}

\section{The contents of the exercise prescribed teaching in vocational college}

The so-called 'the exercise prescribed teaching in vocational college' means that teachers need to make some specific movement requirements and objectives for different students with their practical situation. And teachers could assign appropriate movement type and intensity according to their different stages and practical situations. To be simple, teachers direct students choose suitable physical activity and make a suitable physical intensity by theoretical knowledge and practical situation, the aim is to promote students participate physical activities positively and invigorate health effectively. There are four aspects: choosing a suitable sport item, defing physical intensity with student's health situation, determining movement frequency with students's constitution, determining sport time. To choose a suitable sport event, should consider student's physica situation and try to achieve student's real body-building objective. For example: teachers would arrange some aerobic exercises, such as walk, bicycle riding and swimming when students want to lose weight; teachers would recomend some items, such as running, climb stairs and swimming, when studetns want to invogorate health; teachers would recommend some sports ,such as abdominal crunch or push-up, if students want to shape a good body ${ }^{[2]}$.

\section{The stage division of the exercise prescribed teaching in vocational college}

There are two stages: the first one is preparatory phase. Before, teachers should exam student's constitution and make an analysis on the results, and then determine a suitable objectives with these conclusion. After determination of teaching objective, teachers should formulate a teaching programme and contents. Then teachers should explain some relevant knowledge about physical knowledge, exercise prescription and rehabilitation and evaluation, and then help students set up correct outlook on life and values. The second phase is implementation phase. Students have studied these basic physical knowledge, so teachers could direct them some correct items and give them autonomous rights. Meanwhile students could determine their own exercise prescription and take some adjustment on the basis of their detection result.

\section{The feasibility analysis on the impliementation of teaching of exercise prescribed teaching in vocational college}

The exercise prescribed teaching conforms to the basic belief of physical education and health course standard, and it is high of scientificity.

As the deepen of reforms, the new curriculum standard and physical education promote a basic belief. This belief refers to that focus on student's development, and teach students skills from various angles, and meanwhile promote individuation. In the traditional education, the aim of teaching programme is only to achieve the aim without taking student's practical situation into consideration. So, these teaching programme makes physical exercise be a assignment and students could not find anything happiness. Students have different physical quality, some would be injured if teachers teach them with unified standard, what's worse is some could not be willing to physical exercise and achieve theri physical intention ${ }^{[3]}$. In consideration of these situations, teachers change their way of teaching gradually, they apply the way of exercise prescribed. This model requires teachers determine a sutiable programme for every student beacause of their own situations and achieve the goal. For the reason that this model is correspondence with the requirement for teachers and new curriculum standard, it is imperative to carry out the exercise prescribed.

\section{Meeting to the requirement of society development and practical}

With the development of society, the requirement of society to physical education has changed, the traditional teaching model could not satisfy the needs of society. So the application of the exercise prescribed teaching is inevitable. Because our country has developed rapidly, so the living quality is the same. Under this situation, the student's consititution is changed to overnutrition from undernutrition. In addition, many students are addicted to Internet, so they have less time to exercise, these are the reason of bad health. This new model could help studetn to uptake nutrition and 
strengthen their habitus. It is suitable for the development of society, and have been more and more extensive.

\section{The implementing measures of exercise prescribed teaching in vocational college}

This teaching of exercise prescribed is part of effective. To examine its effect, we could apply a way of experimental comparision. The vocational college could set up two classes, one is experimental group, the other is control group. Both the test site and facilities and teachers are similar, the only different is the way of teaching. In experimental group, teachers apply the way of exercise prescribed, ther other apply the tradational model. And we compare these two differernt results, and come to an conclusion. The specific component are as follows:

Firstly, teachers need to look into the practical situations of students. They need to make an investigation on student's age, weight, anamnesis and sports hobby. These basic conditions are the foundation of the exercise prescribed teaching. Therefore, teachers should pay attention to these works.

Secondly, take performance testing on students. Every student has different institution, teachers should take performance testing on students and determine their physical activity level, load degree and exercise intensity with the results, and then need to test student's heart rate and the maximum oxygen absorbed, and make sure the teaching programme is correct.

Thirdly, precess of the policy-making and its implementation. After teachers finish the test work, they can make plan with suitable sports time and frequency and intensity with these text results.

Fourthly, make an evaluation to exercise prescribed. In this phase, teachers need to check student's physical function, and compare these two results. By this comparison, we could take an evaluation and determine if the teaching of exercise prescribed works. Teahcers should adjust teaching scheme by this evaluation. The aim is to improve the teaching of exercise prescribed constantly, and make an scientific, suitiable teaching scheme ${ }^{[4]}$.

\section{The influence of the application of exercise prescribed teaching in vocational college}

\section{Change the physical function of vocational college}

The effective application of the teaching exercise prescribed has changed the pyhsical function of vaocational college from teaching knowledge to service and management. The aim has also changed, is not the teaching task ,but to design and arrange teaching contents with the needs of student's practical institution. Now, the core function is service management, and it is suitable for the development of vocational college.

\section{Change the teaching management model of vocational college}

The traditional physical teaching manegement applies enclosed model. This model could not keep pace with the society. In consideration of this situation, those vocational college applies free and open management models. In the new management model, the core is network administration. The vocational college reveal a free and lucency physcial management to students through network platform, and also stimulate those students to participate and manage.

\section{Change the classroom-based teaching model}

In traditional physical education, teachers focus on classroom teaching which leads students to lose interests of learning. The way of exercise prescribed teaching could solve this problem, this teaching model is focus on students, they apply flexible but effective multiple teaching ${ }^{[5]}$ with the $^{\text {th }}$ requirements of students. Among them, network instruction become more and more popular, and has been a carrier of the exercise prescribed teaching.

\section{Summary}

In conclusion, the way of exercise prescribed teaching in vocational college is significant for the improvement of physical teaching. Although this model has achieved some effects, it has something unsuitable, so those vocational college would make some promotion in teaching practice. Meanwhile, 
those vocational college should increase propaganda ram about this new teaching model and help more and more teachers and students understand this new model. Therefore, students could enjoy the sports and strengthen their own body.

\section{References}

[1] Qingna Wu, The exploration of the exercise prescribed teaching in vocational college . Sporting Goods and Technology, 2014(10):126.

[2] Liliang Cao, the exploration of the exercise prescribed teaching in vocational college . Space time of sport, 2011 (6):156.

[3] Yang Geng, The application of the exercise prespribed teaching in vocational college Time Education (Education Teaching Version), 2011(3):155.

[4] Yang Lu, the exploration of the exercise prescribed teaching in vocational college-----take Wuhan Vocational Technology College. Chinese Market, 2011(44):166-168.

[5] Yang Lu,The survey on the practicability of the exercise prescribed teaching in vocational college, Journal of Hubei Television and Radio Broadcasting University, 2011, 31(5): 45- 46. 